\title{
CRYOGENIC INSULATION SYSTEM FOR SOFT VACUUM
}

\author{
S. D. Augustynowicz ${ }^{1}$ and J. E. Fesmire ${ }^{2}$ \\ ${ }^{1}$ Dynacs Engineering Company, Inc., DNX-3 \\ Kennedy Space Center, Florida 32899, USA \\ ${ }^{2}$ NASA Kennedy Space Center, MM-J2 \\ Kennedy Space Center, Florida 32899, USA
}

\begin{abstract}
The development of a cryogenic insulation system for operation under soft vacuum is presented in this paper. Conventional insulation materials for cryogenic applications can be divided into three levels of thermal performance, in terms of apparent thermal conductivity [k-value in milliwatt per meter-kelvin $(\mathrm{mW} / \mathrm{m}-\mathrm{K})]$. System k-values below 0.1 can be achieved for multilayer insulation operating at a vacuum level below $1 \times 10^{-4}$ torr. For fiberglass or powder operating below $1 \times 10^{-3}$ torr, $\mathrm{k}$-values of about 2 are obtained. For foam and other materials at ambient pressure, $\mathrm{k}$-values around 30 are typical. New industry and aerospace applications require a versatile, robust, low-cost thermal insulation with performance in the intermediate range. The target for the new composite insulation system is a $\mathrm{k}$-value below $4.8 \mathrm{~mW} / \mathrm{m}-\mathrm{K}$ (R-30) at a soft vacuum level (from 1 to 10 torr) and boundary temperatures of approximately 77 and 293 kelvin (K). Many combinations of radiation shields, spacers, and composite materials were tested from high vacuum to ambient pressure using cryostat boiloff methods. Significant improvement over conventional systems in the soft vacuum range was demonstrated. The new layered composite insulation system was also shown to provide key benefits for high vacuum applications as well.
\end{abstract}

\section{INTRODUCTION}

The technological developments of this century have led to insulation systems that approached the ultimate limit of performance. More technologies and markets forecast for rapid expansion into the $21^{\text {st }}$ century will require, in many cases, not superinsulations but efficient, low-cost systems for these broader cryogenic markets. The cooperative research program Comparative Study of Cryogenic Vacuum Insulation Systems between NASA Kennedy Space Center and MVE, Inc., was conducted in 1997 through 1998. Details of this study, from an energy and economics viewpoint, can be found in a paper recently submitted to the $20^{\text {th }}$ International Refrigeration Congress. ${ }^{1}$ A main target of the study, which 
is the subject of this paper, was to develop a new soft vacuum insulation system (that is, from about 1 to 10 torr) that provides an intermediate level of performance ( $\mathrm{k}$-value below $4.8 \mathrm{~mW} / \mathrm{m}-\mathrm{K})$. The design should be robust and efficient, providing flexibility in the design, manufacturing, and implementation of a variety of thermal insulation systems.

\section{OVERVIEW OF THERMAL INSULATION IN CRYOGENICS}

Cryogenic insulation system development began around the turn of the century, coinciding with the first liquefaction of key industrial gases during the period 1877 to 1908 . D'Arsonval first demonstrated the vacuum flask in $1887 .^{2}$ This design was significantly improved by Dewar in 1893 by silvering the walls of the flask. The concept of filling the vacuum space with powder was illustrated by Stanley in $1912 .{ }^{3}$ Stanley notes the key advantage that "the same degree of heat insulation may be obtained at a much less reduced gaseous pressure in the vacuous space." Early insulation system designs for cryogenic tanks, shown in Figure 1, were advanced by Dana in 1939 and by Cornell in 1947.,5 Multilayer insulation (MLI), which could provide an order of magnitude improvement in performance, was first demonstrated by Peterson in $1951 .^{6}$ MLI systems were well developed by about 1960 through the work of Matsch, Kropschot, Hnilicka, and others. ${ }^{7,8,9}$

Conventional insulation materials for cryogenic applications can be divided into three categories of apparent thermal conductivity ( $\mathrm{k}$-value): around $30 \mathrm{~mW} / \mathrm{m}-\mathrm{K}$ for materials at ambient pressure, about $1.5 \mathrm{~mW} / \mathrm{m}-\mathrm{K}$ for bulk materials at good vacuum (below $10^{-3}$ torr), and below $0.1 \mathrm{~mW} / \mathrm{m}-\mathrm{K}$ for MLI at high vacuum (below $10^{-4}$ torr) (for boundary temperatures of about 300 and $77 \mathrm{~K}$ ). Thermal performance of MLI degrades rapidly for vacuum levels above $10^{-3}$ torr. In addition to the high vacuum requirement, other drawbacks of MLI are its high inplane heat conduction, sensitivity to compressive loads and edge effects, the extreme care needed during installation, and its limitation to more simple structures. Furthermore, the steps of evacuation, heating, and vacuum retention are costly and time consuming. It is important to recognize that there are three levels of thermal performance for MLI: ideal, laboratory, and actual. Actual system performance is typically several times worse than the laboratory performance and often 10 times worse than the ideal. ${ }^{10,11}$

An insulation system that performs well in soft vacuum fills the performance gap between high vacuum systems (R-1500) and ambient pressure systems (R-5), representing a substantial new market area. The expansion of process applications at extreme temperatures combined with the need for higher energy efficiencies translates to an increasing demand for improved thermal insulation systems.

\section{EXPERIMENTAL METHODS}

The liquid nitrogen boiloff method using a cylindrical cryostat with sleeve was used for all tests. The system and corresponding methods are further described in a paper by Fesmire and Augustynowicz. ${ }^{12}$ Continuously rolled materials were installed around a copper sleeve that was then slid onto the vertical cold mass of the cryostat. Sensors were placed between layers of the insulation to obtain temperature-thickness profiles. The temperatures of the cold mass (maintained at $77.8 \mathrm{~K}$ ), the sleeve [cold boundary temperature (CBT)], the insulation outer surface [warm boundary temperature (WBT)], and the vacuum can were measured. The cold vacuum pressure (CVP) was adjusted for the desired vacuum level. Test articles were, in most cases, heated and pumped to below $10^{-4}$ torr to begin the test series. The residual gas was nitrogen for all tests. When the vacuum level, all temperatures, and the boiloff flow are stable, the k-value is determined from Fourier's law of heat conduction for a cylindrical wall. All tests were run with the same copper sleeve outfitted with six surface temperature sensors. The CBT was constant at around $80 \mathrm{~K}$. 


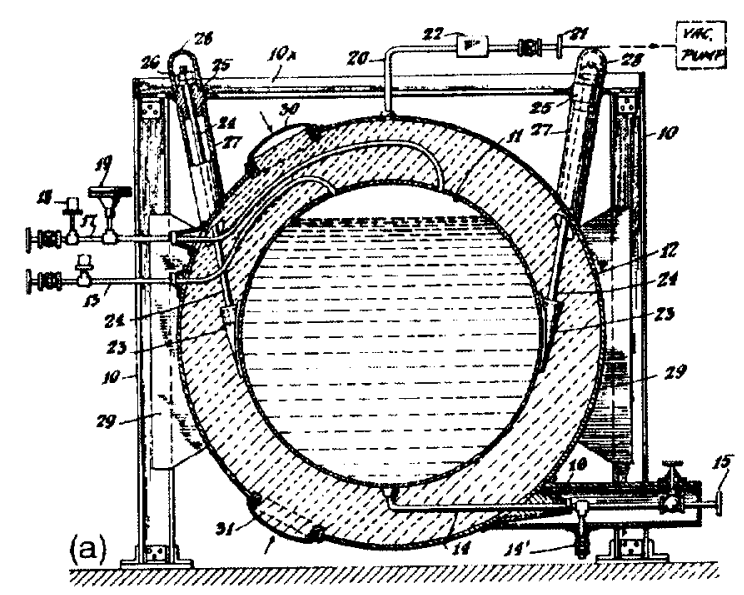

(a)

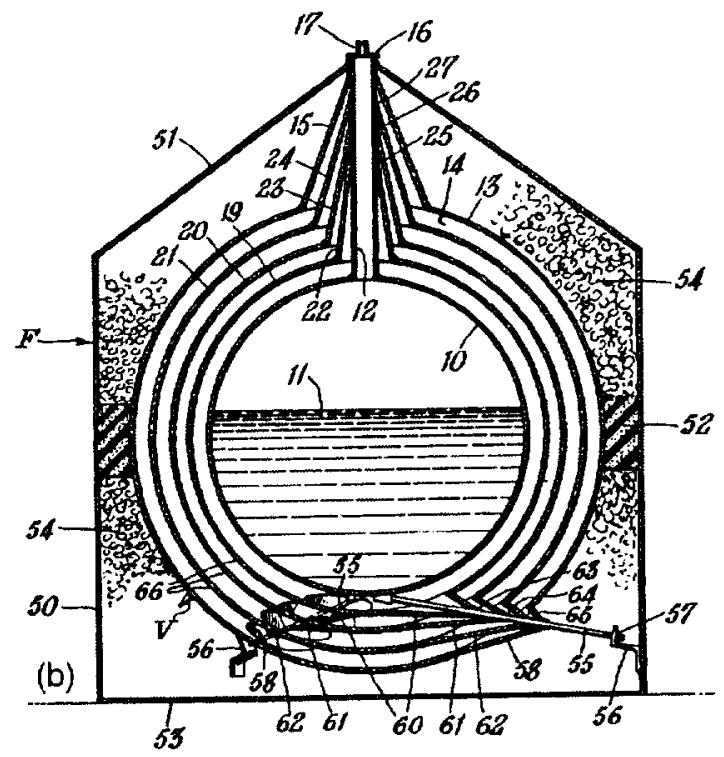

(b)

Figure 1. Early insulation system designs for cryogenic tanks: (a) double-walled tank with evacuated pow$\mathrm{der}^{5}$ and (b) vacuum-insulated container with multiple radiation shields ${ }^{6}$.

The outer heat shroud was maintained at approximately $313 \mathrm{~K}$, which gave WBT ranging from $290 \mathrm{~K}$ (at high vacuum levels) down to about $190 \mathrm{~K}$ (for near ambient pressure).

\section{INSULATION MATERIALS}

Conventional commercially available materials were tested for reference and calibration purposes. Novel materials and unique combinations of conventional materials were also tested. The test articles included combinations of aluminum foil, fiberglass paper, polyester fabric, silica aerogel composite blanket, fumed silica, silica aerogel powder, and syntactic foam. Characteristics of the syntactic foam test article are given by Tupper. ${ }^{13}$ Further description of the aerogel materials is given by Fesmire, Rouanet, and Ryu. ${ }^{14}$ Standard industrial MLI composed of a reflective shield (aluminum foil $0.00724 \mathrm{~mm}$ thick) and spacer (fiberglass paper $0.061 \mathrm{~mm}$ thick) at a density of 1.8 layers per mm served as the benchmark for comparison with other material systems. The installed thickness for most test articles was around $25 \mathrm{~mm}$. This paper focuses on a layered composite insulation system that includes aluminum foil for reflective shields and novel materials for spacers.

\section{TEST RESULTS}

A total of 142 tests of 17 different insulation systems was performed. Table 1 reports the key measurements and conditions for select test articles. The key data points are those at high vacuum $\left(10^{-4}\right.$ torr) and soft vacuum $(0.1,1$, and 10 torr $)$. The boundary temperatures given in the table must be considered for accurate comparison with the measurements 
reported by others. Figure 2 gives a summary of the variation of apparent thermal conductivity with CVP for four groups of material systems: (a) MLI systems (and a syntactic foam system for reference), (b) layered composites with paper, (c) layered composites with fabric, and (d) aerogel composite blankets. The benchmark MLI system (C108) is in good agreement with the experimental data for similar systems as reported by Kaganer, Hnilicka, and Black. ${ }^{2,9,15}$ The Kaganer line in Figure 1(a) is for the following system: aluminum foil and fiberglass spacer, 1.5 layers per $\mathrm{mm}, 293$ and $90 \mathrm{~K}$ boundary temperatures, and air as residual gas. Summaries of the temperature profiles of representative materials, which can be used to estimate thermal conductivity as a function of temperature, are presented in Figure 3. Overall views of the apparent thermal conductivity measurements as a function of CVP are shown in Figure 4.

Table 1. Summary of measurements and conditions for select test articles.

\begin{tabular}{|c|c|c|c|c|c|c|c|}
\hline $\begin{array}{l}\text { Test } \\
\text { No. }\end{array}$ & $\begin{array}{c}\text { Description of Insulation } \\
\text { System }\end{array}$ & $\begin{array}{c}\text { Installed } \\
\text { Density } \\
\left(\mathrm{kg} / \mathrm{m}^{3}\right)\end{array}$ & $\begin{array}{c}\text { Total } \\
\text { Thickness } \\
\text { (mm) } \\
\end{array}$ & $\begin{array}{l}\text { CVP } \\
\text { (torr) } \\
\end{array}$ & $\begin{array}{c}\text { k-value } \\
(\mathrm{mW} / \mathrm{m}-\mathrm{K}) \\
\end{array}$ & $\begin{array}{l}\text { CBT } \\
\text { (K) }\end{array}$ & $\begin{array}{l}\text { WBT } \\
\text { (K) }\end{array}$ \\
\hline $\mathrm{ClO2}$ & $\begin{array}{l}\text { Aerogel composite blanket } \\
\text { (silica aerogel / fiber matrix), } \\
21 \mathrm{~mm} \text {, plus } 10 \text { layers MLI }\end{array}$ & 81 & 30.2 & $\begin{array}{r}0.0001 \\
0.001 \\
0.1 \\
\end{array}$ & $\begin{array}{r}0.19 \\
0.34 \\
2.9 \\
\end{array}$ & $\begin{array}{l}91 \\
91 \\
86 \\
\end{array}$ & $\begin{array}{l}286 \\
285 \\
289 \\
\end{array}$ \\
\hline $\mathrm{C} 104$ & Syntactic foam composite & 107 & 39.9 & $\begin{array}{r}0.0003 \\
0.150 \\
1 \\
10 \\
\end{array}$ & $\begin{array}{l}7.10 \\
13.2 \\
12.8 \\
13.3 \\
\end{array}$ & $\begin{array}{l}80 \\
80 \\
80 \\
80 \\
\end{array}$ & $\begin{array}{l}127 \\
192 \\
192 \\
184 \\
\end{array}$ \\
\hline $\mathrm{Cl05}$ & $\begin{array}{l}\text { Aerogel composite blanket } \\
\text { with carbon dispersion, } 20 \\
\text { mm, plus } 10 \text { layers MLI }\end{array}$ & 79 & 27.9 & $\begin{array}{r}0.0002 \\
0.1 \\
1 \\
10 \\
\end{array}$ & $\begin{array}{l}0.23 \\
3.06 \\
4.54 \\
6.63 \\
\end{array}$ & $\begin{array}{l}91 \\
86 \\
86 \\
86 \\
\end{array}$ & $\begin{array}{l}280 \\
260 \\
248 \\
226 \\
\end{array}$ \\
\hline $\mathrm{C} 107$ & $\begin{array}{l}\text { Layered composite insulation } \\
\text { with fiberglass paper and } \\
\text { fumed silica dispersion }\end{array}$ & 52 & 24.8 & $\begin{array}{r}0.0001 \\
0.1 \\
1 \\
10 \\
\end{array}$ & $\begin{array}{l}0.09 \\
1.23 \\
2.40 \\
6.07 \\
\end{array}$ & $\begin{array}{l}91 \\
88 \\
90 \\
91 \\
\end{array}$ & $\begin{array}{l}281 \\
279 \\
269 \\
225 \\
\end{array}$ \\
\hline $\mathrm{Cl08}$ & $\begin{array}{l}\text { MLI (aluminum foil and fi- } \\
\text { berglass paper spacer), } 40 \\
\text { layers at } 1.8 \text { layers } / \mathrm{mm}\end{array}$ & 58 & 22.3 & $\begin{array}{r}0.0005 \\
0.1 \\
1 \\
10 \\
\end{array}$ & $\begin{array}{l}0.08 \\
2.68 \\
9.01 \\
13.6 \\
\end{array}$ & $\begin{array}{l}87 \\
90 \\
92 \\
94 \\
\end{array}$ & $\begin{array}{l}281 \\
256 \\
196 \\
181 \\
\end{array}$ \\
\hline $\mathrm{C} 109$ & $\begin{array}{l}\text { Layered composite insulation } \\
\text { with polyester fabric and } \\
\text { fumed silica dispersion }\end{array}$ & 59 & 28.7 & $\begin{array}{r}0.0001 \\
0.1 \\
1 \\
10 \\
\end{array}$ & $\begin{array}{l}0.24 \\
1.91 \\
4.81 \\
9.66\end{array}$ & $\begin{array}{l}95 \\
87 \\
87 \\
88 \\
\end{array}$ & $\begin{array}{l}269 \\
267 \\
242 \\
215 \\
\end{array}$ \\
\hline $\mathrm{Cl10}$ & $\begin{array}{l}\text { Aerogel composite blanket } \\
\text { (silica aerogel / fiber matrix), } \\
2 \text { layers, } 16 \mathrm{~mm} \text { each layer }\end{array}$ & 125 & 32.0 & $\begin{array}{r}0.0001 \\
0.1 \\
1 \\
10 \\
\end{array}$ & $\begin{array}{l}0.55 \\
1.16 \\
3.31 \\
5.80 \\
\end{array}$ & $\begin{array}{l}86 \\
86 \\
85 \\
85 \\
\end{array}$ & $\begin{array}{l}214 \\
278 \\
265 \\
246 \\
\end{array}$ \\
\hline $\mathrm{C} 113$ & $\begin{array}{l}\text { Layered composite insulation } \\
\text { with fiberglass paper and } \\
\text { fumed silica dispersion }\end{array}$ & 51 & 20.9 & $\begin{array}{r}0.0003 \\
0.1 \\
1 \\
10 \\
\end{array}$ & $\begin{array}{l}0.12 \\
1.34 \\
2.93 \\
7.71 \\
\end{array}$ & $\begin{array}{l}84 \\
80 \\
81 \\
83 \\
\end{array}$ & $\begin{array}{l}284 \\
273 \\
244 \\
211 \\
\end{array}$ \\
\hline $\mathrm{C} 114$ & $\begin{array}{l}\text { Layered composite insulation } \\
\text { with fiberglass paper and } \\
\text { fumed silica dispersion }\end{array}$ & 53 & 24.2 & $\begin{array}{r}0.0001 \\
0.1 \\
1 \\
10 \\
\end{array}$ & $\begin{array}{l}0.15 \\
1.11 \\
2.66 \\
6.82 \\
\end{array}$ & $\begin{array}{l}88 \\
80 \\
81 \\
83 \\
\end{array}$ & $\begin{array}{l}278 \\
286 \\
265 \\
232 \\
\end{array}$ \\
\hline $\mathrm{C} 115$ & $\begin{array}{l}\text { Layered composite insulation } \\
\text { with polyester fabric and } \\
\text { fumed silica dispersion }\end{array}$ & 64 & 25.1 & $\begin{array}{r}0.0001 \\
0.1 \\
1 \\
10 \\
\end{array}$ & $\begin{array}{l}0.28 \\
1.51 \\
3.85 \\
8.78 \\
\end{array}$ & $\begin{array}{l}93 \\
86 \\
84 \\
88 \\
\end{array}$ & $\begin{array}{l}271 \\
276 \\
263 \\
219 \\
\end{array}$ \\
\hline $\mathrm{C} 116$ & $\begin{array}{l}\text { Layered insulation with poly- } \\
\text { ester fabric }\end{array}$ & 51 & 18.7 & $\begin{array}{r}0.0001 \\
0.1 \\
1\end{array}$ & $\begin{array}{l}0.15 \\
4.98 \\
8.49\end{array}$ & $\begin{array}{l}93 \\
89 \\
89\end{array}$ & $\begin{array}{l}284 \\
234 \\
200\end{array}$ \\
\hline
\end{tabular}




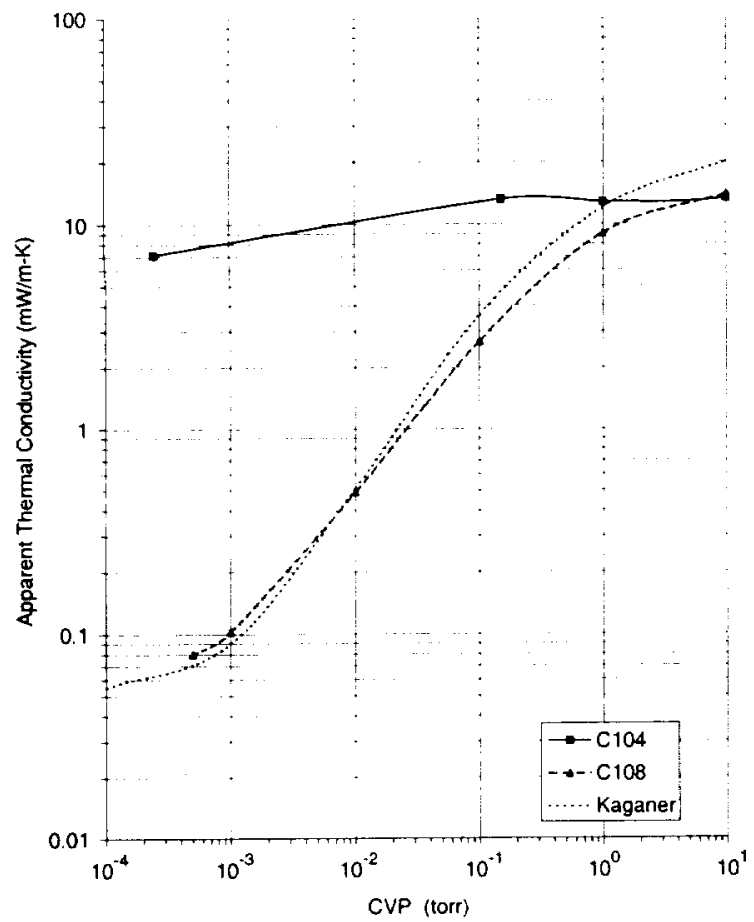

(a)

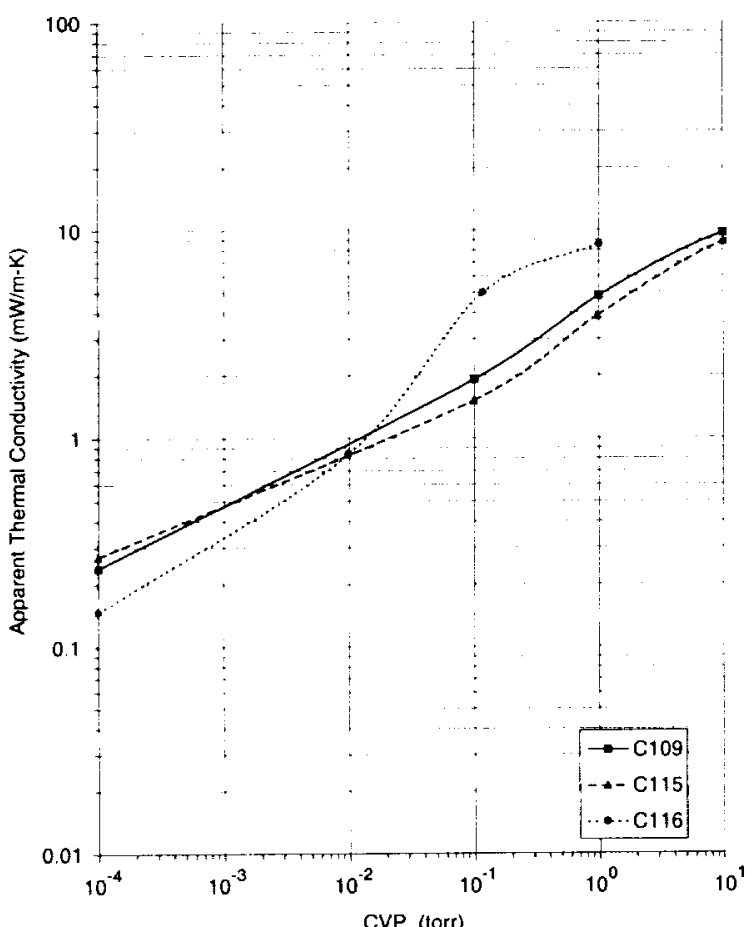

(c)

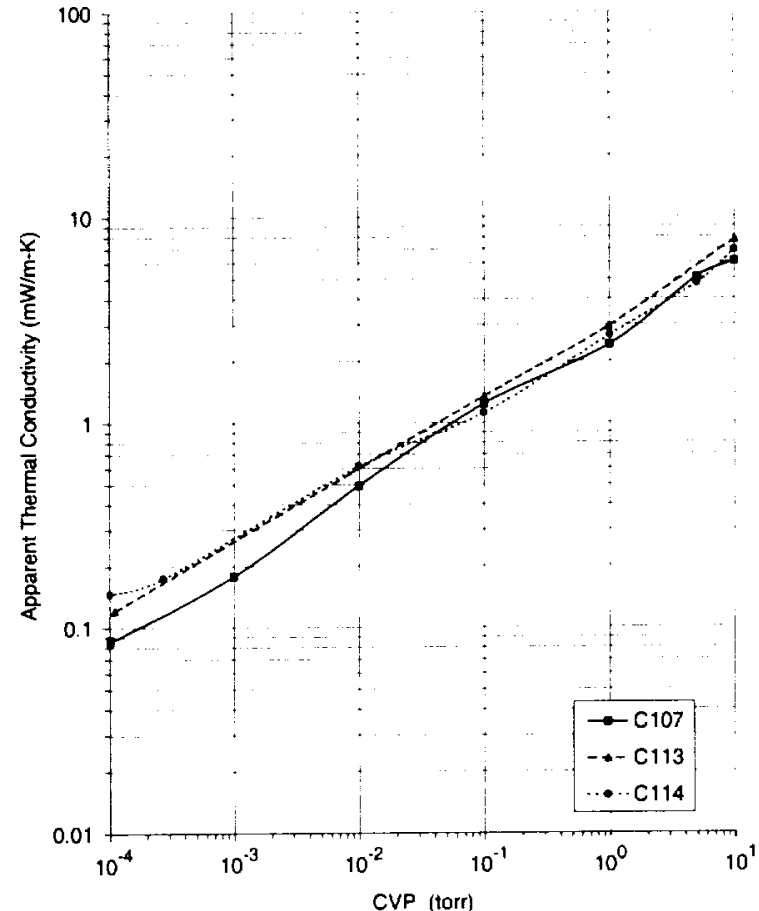

(b)

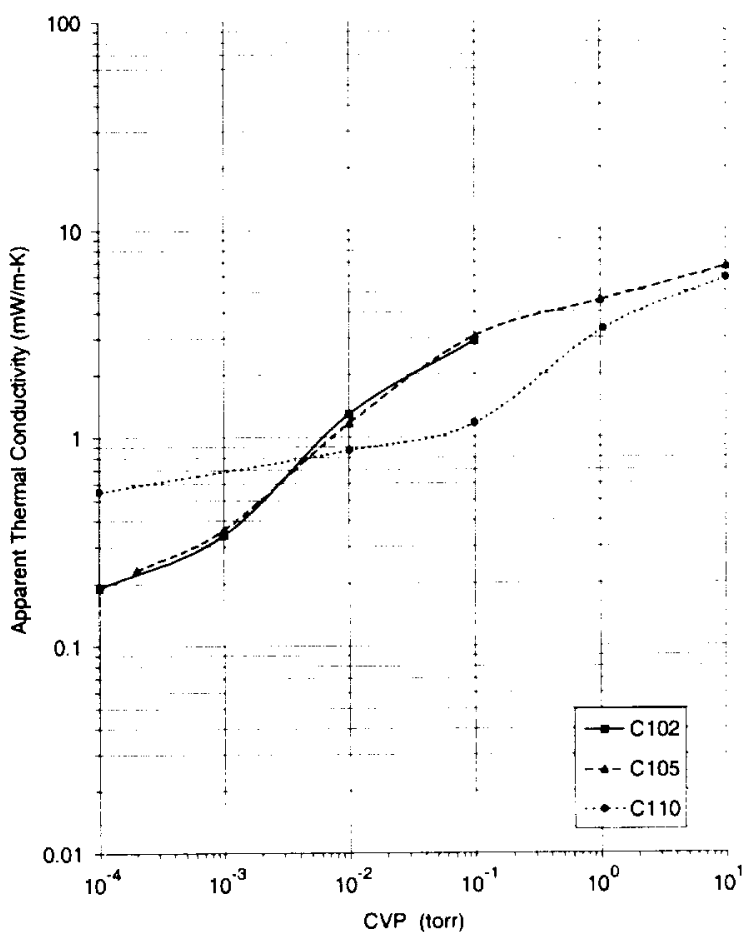

(d)

Figure 2. Variation of apparent thermal conductivity with CVP: (a) MLI and foam, (b) layered composite insulation with paper, (c) layered composite insulation with fabric, and (d) aerogel composite blankets. 


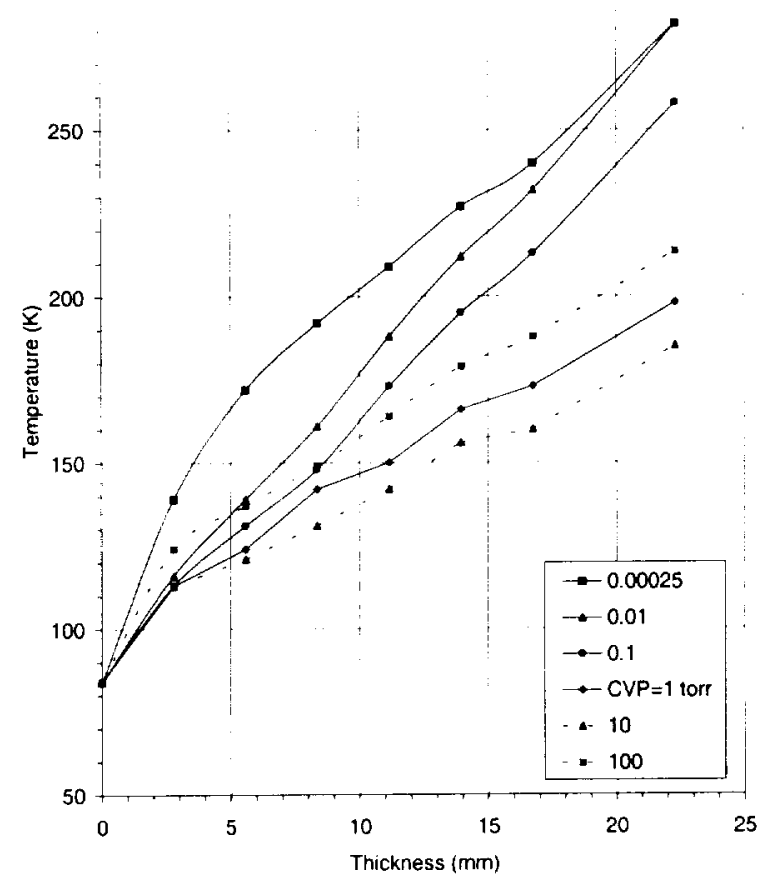

(a)

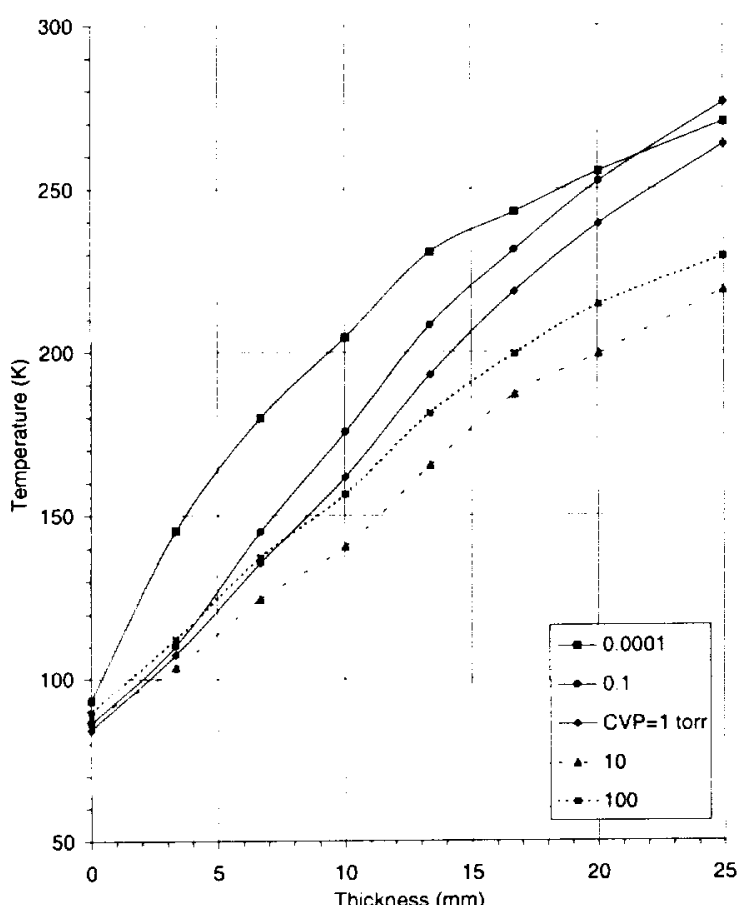

(c)

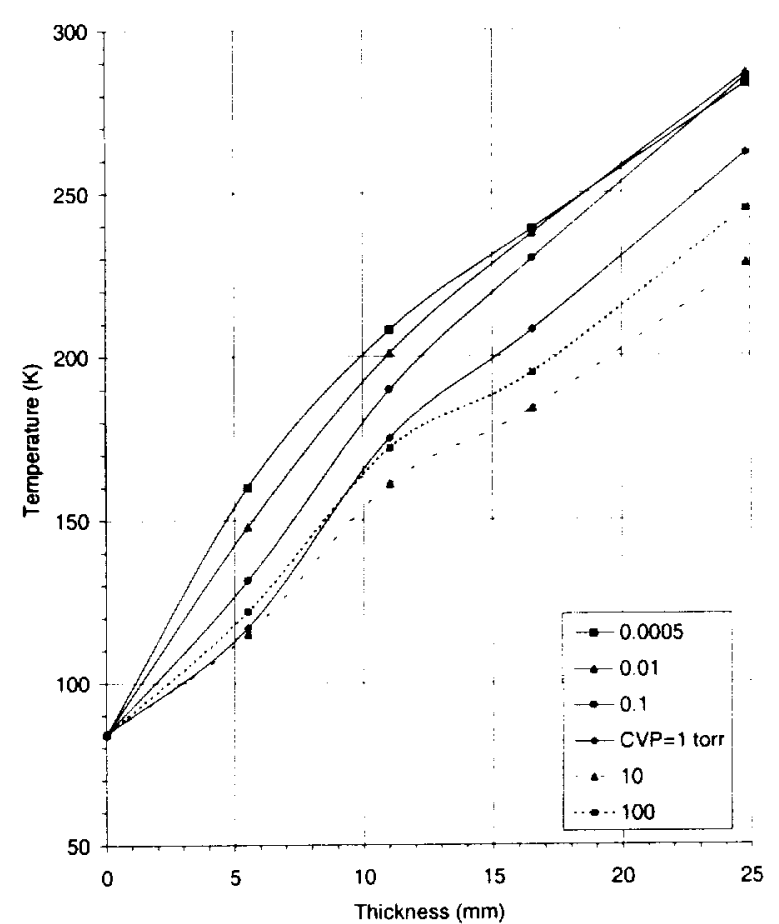

(b)

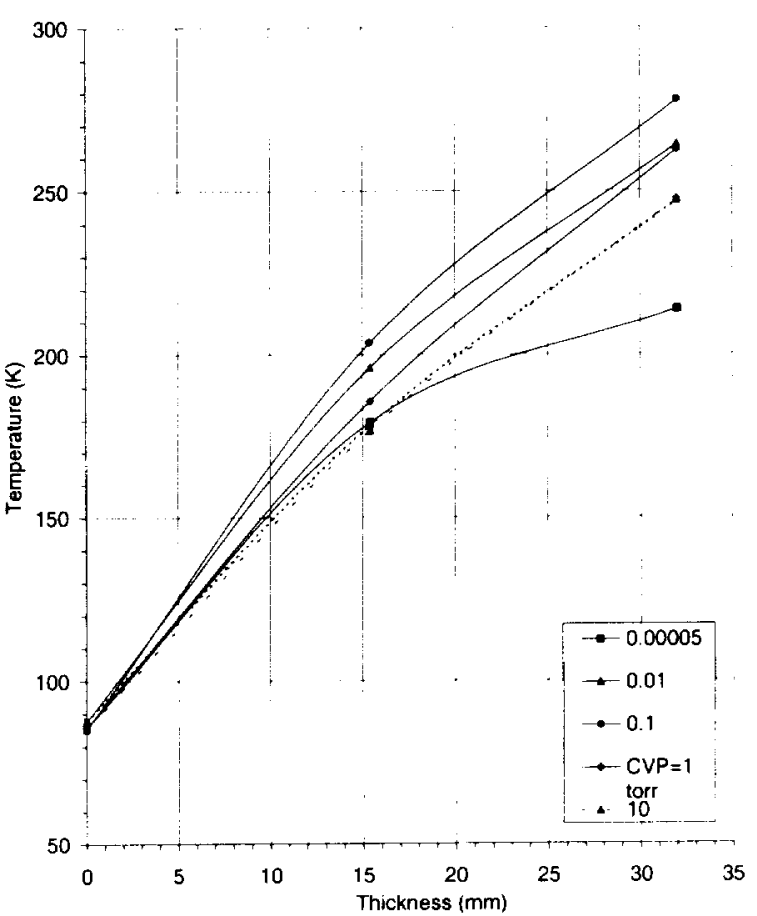

(d)

Figure 3. Temperature profiles through insulation at different vacuum levels: (a) MLI, (b) layered composite insulation with paper, (c) layered composite insulation with fabric, and (d) aerogel composite blankets. 


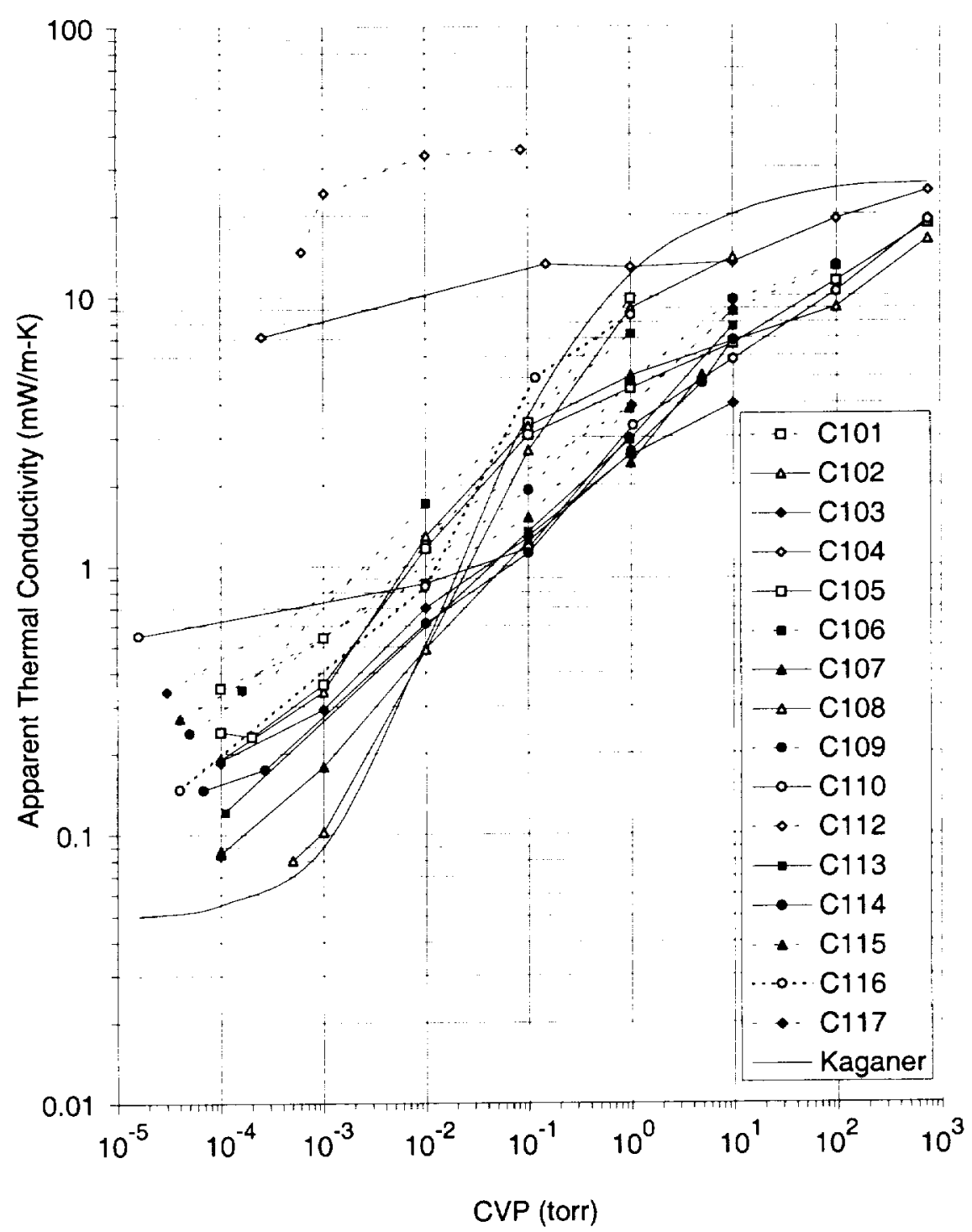

Figure 4. Overall view of liquid nitrogen boiloff measurements: apparent thermal conductivity as a function of CVP.

\section{SYSTEM DESIGN CONSIDERATIONS}

The appropriate choice of a thermal insulation system depends on matching the performance level with the overall cost. That is, the performance must justify the cost. Consideration of the actual operating conditions and an estimation of the total heat leak of the mechanical system is needed to determine the insulation requirements. The amount of heat flow through the insulation relative to the amount of heat flow from all the other sources must be understood in order to select an appropriate insulation system. The main factors to consider are: (1) operating conditions of the system, (2) total heat leak of the mechanical system, (3) material properties such as density and compatibility, and (4) method of testing and evaluation. Attention should also be given to offering advantages in easier fabrication, maintenance, and modification where possible. For the cost of a bulk storage container (with standard MLI), more than 25 percent is attributed to the insulation. ${ }^{16}$ The materials are only a small fraction of this cost; but the heating, vacuum pumping, testing, material handling, and other steps necessary for manufacturing a high-vacuum vessel are costly. In summary, the overall effectiveness of the insulation system design depends on: (1) thermal performance, (2) versatility and durability, (3) ease of use in manufacturing and installation, and (4) costs of operations and maintenance. 


\section{CONCLUSIONS}

A number of the presented systems have $\mathrm{k}$-values better than the target $4.8 \mathrm{~mW} / \mathrm{m}-\mathrm{K}$ (R-30) at a 1-torr vacuum level and boundary temperatures of approximately 280 and $80 \mathrm{~K}$. For example, the layered composite $\mathrm{C} 107$ gave superior performance of $2.4 \mathrm{~mW} / \mathrm{m}-\mathrm{K}$ (R$60)$ at 1 torr which is about four times better than the benchmark MLI C108. The layered composite insulation systems are targeted for low-cost, intermediate performance uses but were found to offer advantages in high-vacuum superinsulation applications as well. Thermal performance of the layered composite with paper was comparable to the benchmark MLI at high vacuum $(0.09$ versus $0.08 \mathrm{~mW} / \mathrm{m}-\mathrm{K})$. The actual performance of the more robust composite could exceed that of highly evacuated MLI systems when the factors of edge effects and compression are considered. The "vacuum burden" of fabricating 1 -torr systems versus 0.0001 -torr systems is accordingly reduced. The new layered composite is being developed into a family of thermal insulation systems, targeting both soft vacuum and high vacuum cryogenic applications. Work on material optimization and application design is currently being performed at the Cryogenics Test Laboratory at NASA Kennedy Space Center.

\section{REFERENCES}

1. S.D. Augustynowicz, J.E. Fesmire, and J.P. Wikstrom, Cryogenic insulation systems, $20^{\text {th }}$ International Refrigeration Congress, Sydney, 1999.

2. M.G. Kaganer, "Thermal Insulation in Cryogenic Engineering," Israel Program for Scientific Translations, Jerusalem, 1969.

3. W. Stanley, Heat-insulated receptacle, US Patent No. 1,071,817, 1912.

4. L.I. Dana, Insulated container for liquefied gases and the like, US Patent No. 2,396,459, 1939.

5. W.D. Cornell, Radiation shield supports in vacuum insulated containers, US Patent No. 2,643,022, 1947.

6. I.A. Black, et al, Development of high-efficiency insulation, Advances in Cryogenic Engineering, Vol. 5, Plenum Press, New York, 1960, pp. 181-188.

7. L.C. Matsch, Thermal insulation, US Patent No. 3,007,596, 1956.

8. R.H. Kropschot, et al, Multiple-layer insulation, Advances in Cryogenic Engineering, Vol. 5, Plenum Press, New York, 1960, pp. 189-197.

9. M.P. Hnilicka. Engineering aspects of heat transfer in multilayer reflective insulation and performance of NRC insulation, Advances in Cryogenic Engineering, Vol. 5, Plenum Press, New York, 1960, pp. 199208.

10. American Society for Testing Materials, ASTM C740, Standard practice for evacuated reflective insulation in cryogenic service, 1996.

11. T. Nast, Multilayer insulation systems, In: Weisend, J., Handbook of Cryogenic Engineering, Taylor and Francis, Philadelphia, 1998, pp. 195-196.

12. J.E. Fesmire and S.D. Augustynowicz, Insulation testing using cryostat apparatus with sleeve, Cryogenic Engineering Conference, Montreal, 1999.

13. M. Tupper, Composite Technology Development, Inc., Insulation, adhesives, and coatings specially formulated for space cryogenic applications, Space Cryogenics Workshop, University of Oregon, 1997.

14. J. Fesmire, S. Rouanet, and J. Ryu, Aerogel-based cryogenic superinsulation, Advances in Cryogenic Engineering, Vol. 44, Plenum Press, New York, 1998, pp. 219-226.

15. I.A. Black and P.E. Glaser, Progress report on the development of high-efficiency insulation, Advances in Cryogenic Engineering, Vol. 6, Plenum Press, New York, 1960, pp. 32-41.

16. J. Wikstrom, personal communication, MVE, Inc., Burnsville, MN. 